\title{
Editorial
}

\section{Integration and specialism: complementary not contradictory}

\author{
Stephen Pereira ${ }^{1}$, Daniel Dalton ${ }^{2}$ \\ ${ }^{1}$ Consultant Psychiatrist, Pathways Psychiatric Intensive Care Unit; Honorary Senior Lecturer, \\ Guy's, King's \& St Thomas' School of Medicine; Chairman, NAPICU; ${ }^{2}$ Staff Grade Psychiatrist, Pathways \\ Psychiatric Intensive Care Unit
}

Psychiatry, behavioural disturbance and risk management have conceptually coexisted for hundreds of years, however, prior to the 1800 Criminal Lunatics Act, drafted exigently following an attempt on the life of the then King by the "insane" Hadfield, the only means of care was custodial, under arcane vagrancy legislation, such as the 1714 Vagrancy Act, or on the basis of the poor laws. Mentally disordered individuals were either incarcerated as criminals or paupers (Select Committee, 1807) falling under the responsibility of local parish councils. At this point, incarceration was just that, with prisons hosting most detained mentally disordered individuals, under the indefinite see of the monarch. The first vision for caring, secure, environments for mentally disordered individuals was in the development of asylums following the 1808 County Asylums Act, which recognised that detaining, "lunatics and other insane persons.... in Gaols, Houses of Correction, Poor Houses and Houses of Industry, is highly dangerous and inconvenient."

The first recognition of need, when managing risk and mental disorder, for the commissioning of specialist services, was probably in 1815 , when a governmental select committee recognised that the country's "criminal lunatics" required some special care, as opposed to the "pauper lunatics"; and ordered the development of specialist wings, in the Bethlem Hospital, to hold up to 60 people detained under

Correspondence to: Dr Stephen Pereira, Pathways Psychiatric Intensive Care Unit, Goodmayes Hospital, Barley lane, Ilford. IG3 8XJ, UK. Tel: 0208980 5833; E-mail: Stephen.Pereira@nelmht.nhs.uk the 1800 Act. In reporting to the committee in respect of the management of disturbed behaviour, Wakefield, quoted in Mental Health History Timeline, noted of a client in the Bethlem, prior to this development, "A stout ring was rivetted round his neck, from which a short chain passed to a ring made to slide upwards or downwards on an upright massive iron bar... Round his body a strong iron bar about two inches wide was rivetted. . . which being fashioned to and enclosing each of his arms, pinioned them close to his sides. . . bars . . passing over his shoulders, were rivetted to the waist bar both before and behind..." (Edward Wakefield to Select Committee in 1815). It is unlikely that the situation improved greatly in the more specialist services of the day.

By the middle of the 19th century there were 436 such criminal lunatics housed in general asylums across the country, and, of these, 100 were still in the Bethlem hospital. In search of a solution, Broadmoor was opened in 1863 and received its first intake, of all of the criminal lunatics from the Bethlem Hospital, one year later. It was perhaps at this point that the split between locked and civil psychiatry arose for the first time.

This division was not only along judicial lines, although clinical distinction seemed to have a low priority. It remained the case that acutely disturbed individuals who had not committed a crime should be managed in poor houses. As is noted in the 1890 Lunatics Act, the first Act to properly seek to protect the rights of detained patients, when an emergency psychiatric situation occurred, "The alleged lunatic should, before any such 
proceedings can be taken, be placed under care and control... the constable... may remove the alleged lunatic to the workhouse of the union in which the alleged lunatic is . . . but no person shall be so detained for more than three days ..." (Section 20). Whereas those with means, and disturbed behaviour, would be placed in "an institution for lunatics" for up to 7 days (Section 11) at the behest of their husband or wife.

As the number of individuals detained across the country increased, in 1910 Rampton was opened, and Moss Side in 1930, to be commissioned as the State's institutions for dangerous, mentally disordered individuals. Along with Broadmoor, they achieved hospital status on the inception of the National Health Service in 1948. Despite this, these hospitals remained under separate management by the Board of Control, a central government committee, up until the 1959 Mental Health Act, when this responsibility passed to the caring professions.

Following the inception of the Royal College of Psychiatrists in 1971, the Glancy Report on Disturbed and Dangerous Patients (1974) and the Butler Committee Report on Mentally Disordered Offenders (1975) gave birth to the commissioning of Regional Psychiatric Secure Units (later recognised as Medium Secure Units), outside of mainstream psychiatry, even if physically more "local" than the special hospitals. At around the same time, in America, Rachlin coined the term Psychiatric Intensive Care Unit (PICU) to describe one solution to the need for locked wards within a general psychiatric hospital in New York. At the time it was recognised that challenges posed by the non-criminal, psychiatric population including absconding, self-harm, violence, and generally disturbed behaviour, required something other than normal acute ward care; the intention being to address the comparatively poor longterm outcome of a cohort of patients habitually readmitted to hospital, and habitually selfdischarging and disengaging from care (Rachlin, 1973).

Following the full report of the Butler Committee, the government published the white paper "Better Services for the Mentally Ill" (1975), which made specific reference to a move away from large, peripheral asylums and into a system where there would be "a local and better range of facilities" (para 11.5), earmarking funding for local services to develop to meet these needs. Although recognising a need to provide local facilities for "new long stay patients" there was, at this time, little vision of specialist services within the general acute psychiatric hospitals proposed, with the regional and interim secure units still existing outside of the "local" vision for psychiatric healthcare. Secure care remained in "isolation" from the mainstream of NHS care, with a gap in care provision that would only grow as the demand to divert offenders into healthcare expanded.

The Reed report, in 1992, set out a vision of early diversion for mentally disordered offenders into hospital environments, and by 1999 an estimated 150 schemes were diverting offenders from courts into hospital care, in addition to the number of disordered individuals moving from prison, and from the community (NACRO, 2005). Reed made no pretence that acute services would not need to provide locked wards to offer such individuals care, recognising that the RSU's were already stretched beyond capacity in 1992, but made little suggestion as to the operating principles of such units.

In Australia, Goldney described perhaps the first model to clearly define an operating principle for PICUs alongside other services, rather than alongside, and following a large cohort of patients over a three-year period, from 1982 to 1985. The units operated on a short-stay, restraint-dose-medication, basis, without any clear sense of longer-term outcomes, but made the positive step of integrating within the general hospitals, and outside of the custodial sector (Goldney et al., 1985).

Perhaps inevitably, in line with the historical treatment of the acutely unwell, such wards became seen as "dumping grounds" for difficult-tomanage patients, and were often unsophisticated in approaches to treatment (Beer et al., 1997; Zigmond, 1995). When Zigmond published his review of these special care wards in 1995, the UK provision of care for those with disturbed behaviour, or those diverted to hospital and not into the regional secure units, was patchy. Clearly some units existed to provide locked care inside 
mainstream services, but there was still no coherent identity or sense of strategy (Zigmond, 1995). Otherwise disturbed behaviour was often managed by locking the doors of non-specialised, acute wards.

The rest of medicine meanwhile, was moving towards a model of specialism and sub-specialism, with liaison and effective communication between specialities underpinning good practice. The model of makeshift secure care in acute psychiatry would never have been tolerated within the bounds of other medical specialities. The recognition of Psychiatric Intensive Care as a specialism followed the institution of NAPICU in 1996, and was confirmed in the National Service Framework in 1999 refined in the National Minimum Standards for Acute Inpatient services in 2001, which defined a highly detailed concept of PICUs as units for the most unwell of inpatients, offering care with consistently high standards of engagement, activity, and environment, to meet the high level of need of the patients concerned, whilst offering a necessary level of security.

This model of Psychiatric Intensive Care as a speciality in itself is unique in the world today, and despite general cohesion, the units are still sometimes misunderstood. In order to combat the misconceptions that still exist about PICUs and the patients whom they treat, teamwork, good leadership and strong team cohesion seem imperative (Brown \& Wellman, 1998). It is also absolutely necessary for PICU's to interface with acute psychiatric colleagues in order to ensure a fluid, fair, and effective service (DOH, 2001). This integrated type of locked ward must involve putting into practice care plans that can be realistically followed through in the long and short term, and which take account of the needs of patients beyond the initial period of disturbance that might have led to PICU admission. If PICU's are not seen as having a limited and specialist role, integrated with other services, then there is a danger of these units becoming, "de facto long stay low secure units," as described by Brown \& Bass (2004).

The publication of a manual of intensive care psychiatry, (Pereira et al., 2001) perhaps marks the most significant move from the dark ages of psychiatric locked care into an era of consensus and identity. Separate recognition of PICUs and Low-Secure Units, meriting their own National Minimum Standards is the penultimate piece in the commissioning puzzle. Has opened the door to the development of units offering necessary but humane, multidisciplinary, above all therapeutic, safe and secure, high quality care, with specialist staff with an interest in the field. (Department of Health, 2001). By ensuring that objectivity and evidence underpinned the rationale for all decision making, admission and referral criteria. This ensures that the key National Service Framework target for every patient to have "an appropriate hospital bed, which is in the least restrictive environment with the need to protect them and the public, as close to home as possible" (DOH, 1999) was upheld in the provision of PICU care.

The mapping of provisions of Psychiatric Intensive Care across London, as published in the last JPI, shows the great extent to which PICUs are a part of current psychiatric models of care (Pereira et al., 2005). The first comprehensive, national, survey of PICUs and Low Secure Units has now been carried out, with an impressive response rate of 98\%, painting a detailed picture of 144 PICUs and 123 LSUs across the UK. It has been possible, for the first time, to compare characteristics of PICUs, and use this information to make informed decisions about issues such as the optimal staff levels, or necessary number of beds (Pereira et al., in press). The findings mirror the micrographic findings of varying adherence to the National Minimum Standards and ideals found by Brown \& Bass (2004) highlighting the need for concrete procedures to monitor and implement change and ensure improvement, as well as develop evidence base practice for PICU care. My initiative to develop The National PICU Governance Network (Dye \& Johnston, 2005) indicates there is a strategy in place to audit and research best practice in PICUs, however, the ramifications of standardisation and classification of PICU's are not only seen in the improved practice from within the PICU network. Also, following the recent findings of a survey of PICU design and facilities across the UK (Pereira \& Chaudhry, in press) the Department of Health released $f 30$ million of new money, to 28 different Strategic Health Authorities, to improve facilities in PICUs across the UK. 
Furthermore, following the proceedings of the Department of Health's Steering Group recently, recognising the key role for PICUs to be actively involved in managing acutely disturbed behaviour and violence in mental health, the government recently announced the release of a further $£, 130$ million in order to append "Section 136 rooms" to existing PICUs money that will further add to the quality of environment and design of PICUs and humanise treatment of the most disturbed and ill patients.

Following the inception of an MSc in Psychiatric Intensive Care, the specialism has achieved recognition for its academic validity, as well as for the clinical expertise required. The academic distinction brought to bear has enhanced management of acute disturbance in mental illness generally, with exciting developments, perhaps the most significant of which is the national guidance on the management of disturbed behaviour issued by the National Institute for Clinical Excellence (2005). Following the principle that environmental and organisational factors are considered first in managing disturbed behaviour, holding the tenet of prevention as preferable to reaction in crisis, specifying specialist training in the management of acute disturbance for all involved, and ensuring that the perspectives of service users are at the forefront of guidance, the guidance also recognises modern approaches to the pharmacotherapy of disturbed behaviour. Novel antipsychotics such as Risperidone and intramuscular and oral Olanzapine are being used to achieve rapid tranquillisation with hoped-for benefits in terms of lesser side effects and patient satisfaction. Not only might these approaches reflect upon a better understanding of midbrain dopamine and serotonin function in the aetiology of disturbed behaviour, but also follow logically from the humane approach to managing disturbance that modern Psychiatric Intensive Care practice seeks to promote. Were chemical restraint still the maxim, it is unlikely these medications could have found such ready favour. These guidelines follow the lessons learnt from PICU practice at its best, and mirror the model of specialist care with the aim of bringing benefit to patients, and to improve long term outcomes.

It is now hoped to take these developments worldwide. A collaborative approach to PICU design and philosophy in the UK, Australia, New
Zealand and the United States is being planned (Pereira et al., in press) which should bring about a worldwide consensus as to PICU design, from which the evidence base for efficacy of interventions must grow.

It is then, relatively recent in the history of mental health and risk management, that the management of risk and disturbed behaviour in mental illness has come wholly into the hands of specialist health professionals. It is even more recent that this has been in the context of an integrated, specialist, service working within acute adult mental health. This makes all the more remarkable the rapid development of Psychiatric Intensive Care as a specialism within such a short period. Nonetheless, Psychiatric Intensive Care is still the newest psychiatric speciality in the UK, but already shows all the signs of making meaningful impact on quality of care in all areas of inpatient psychiatry. Our target now is to ensure that as this specialism grows, it is not an ivory tower but bridges, with other services and countries, which we build.

\section{References}

Beer, M.D., Paton, C. and Pereira, S. (1997) Hot beds of general psychiatry: a national survey of psychiatric intensive care units. Psychiatric Bulletin. 21(3): 142-144.

Brown, S. and Bass, N. (2004) The psychiatric intensive care unit (PICU): patient characteristics, treatment and outcome. Journal of Mental Health (UK). 13(6): 601-609.

Brown, K. and Wellman, N. (1998) Psychiatric intensive care: a developing speciality. Nursing Standard. 12(29): 45-47.

Butler Report (1975) Report of the Committee on Mentally Abnormal Offenders, CMND 6244. HMSO, London.

County Asylums Act (1808) An Act for the Better Care and Maintenance of Lunatics, being Paupers or Criminals in England. HMSO, London.

Crowhurst, N. and Bowers, L. (2002) Philosophy, care and treatment on the psychiatric intensive care unit: themes, trends and future practice. Journal of Psychiatric and Mental Health Nursing. 9(6): 689-695.

Department of Health (1975) Better Services for the Mentally Ill. A White Paper. HMSO, London.

Department of Health (1999) National Service Framework for Mental Health. Modern Standards and Service Models. HMSO, London.

Department of Health (2001) Mental Health Policy Implementation Guide, Acute Adult Care Provision, pp. 10 \& 24. HMSO, London. 
Department of Health (2001) Mental Health Policy Implementation Guide, National Minimum Standards for General Adult Services in Psychiatric Intensive Care Units and Low Secure Environments. HMSO, London.

Dye, S. and Johnston, A. (2005) After the standards . . . a gaping cavity filled by clinical governance? Journal Of Psychiatric Intensive Care. 1(1): 3-5.

Glancy Report (1974) Working Party Report on security in the NHS, Psychiatric Hospitals. HMSO, London.

Goldney, R., et al. (1985) The psychiatric intensive care unit. British Journal of Psychiatry. 146: 50-54.

NACRO (2005) Findings of the 2004 Survey of Court Diversion/Criminal Justice Mental Health Liaison Schemes for Mentally Disordered Offenders in England and Wales, March 2005. http://nacro.org.uk

National Institute for Clinical Excellence (2005) Clinical Guidance 25: Violence, The Short-Term Management of Disturbed/Violent Behaviour in Inpatient Psychiatric Settings and Emergency Departments, ISBN 1-84257-921-5. NICE.

Pereira, S., Sarsam, M., Bhui, K. et al. (2005) The London survey of psychiatric intensive care units: service provision and operational characteristics of national health service units. Journal of Psychiatric Intensive Care. 1(1): 7-15.
Pereira, S., Beer, M. and Paton, C. (1997) Good Practice Issues In Psychiatric Intensive Care Units. Psychiatric Bulletin. 23(7): 397-400.

Pereira, S., Beer, D. and Paton, C. (2001) Psychiatric intensive care, ISBN: 1-900151-87-1. Greenwich Medical Media Limited, London, England.

Rachlin, S. (1973) On the need for a closed ward in an open hospital: the psychiatric intensive-care unit. Hospital $\mathcal{E}$ Community Psychiatry. 24(12): 829-833.

Reed Report (1992) Report into Mentally Disordered Offenders and Others Who Require Similar Services (CM2088). HMSO, London.

Roberts, A. (1981) Mental Health History Timeline; at http://www.mdx.ac.uk/www/study/MHHTim.htm

Select Committee of the House of Commons (1807) To Inquire into the State of the Criminal and Pauper Lunatics in England and Wales, and the Laws Relating Thereto, PP 1807 (39) vol 2, p. 69. HMSO, London.

Select committee of the House of Commons (1815) Report on Madhouses in England PP 1814-1815 (296) vol 4, pp 801-1034. HMSO, London.

Zigmond, A. (1995) Special care wards: are they special? Psychiatric Bulletin. 19: 310-312. 
https://doi.org/10.1017/S1742646406000215 Published online by Cambridge University Press 